\title{
A Study of Relationship between Hopelessness and Coping Strategies in Cancer Patients
}

\author{
Touseef Rizvi ${ }^{1 *}$
}

\begin{abstract}
Although cancer patients often experience hopelessness and other psychological problems, research on hopelessness and coping strategies is rare. The objectives of this study were to identify the levels of hopelessness experienced and the coping strategies used by breast, colorectal and stomach cancer patients.200 cancer patients (92 disfigured and 108 nondisfigured were included in the sample. Patients completed the sample survey packets comprising of Beck's Hopelessness Scale (Beck, 1974) and Ways of Coping Questionnaire (Lazarus \& Folkman, 1988). Majority of the cancer patients were in moderate level of hopelessness. Seeking social support coping strategy was used most often by the cancer patients and Confrontive coping strategy was used the least. Significant negative correlation existed between hopelessness and use of coping strategies viz. distancing, self-controlling, accepting responsibility, Planful problem solving and positive reappraisal. t-test revealed more hopelessness in disfigured group of cancer patients. t-test also revealed that selfcontrolling and positive reappraisal coping strategies were used less by disfigured group of cancer patients.
\end{abstract}

Keywords: Cancer, Hopelessness, Coping.

For many years there has been interest in how people cope with cancer. Once diagnosed, cancer has the potential to affect nearly every aspect of an individual's life, including the physical, psychological, interpersonal, vocational, and spiritual domains (Aziz, 2007). Compared with individuals who have not had cancer, survivors are more likely to report psychological problems, poorer health, and functional limitations, such as being unable to drive or work (Hewitt, Rowland, \&Yancik, 2003).A strong feeling of hopelessness is known to have the potential to cause new cancer to emerge and to die because of the illness $(\mathrm{Oz}$, 2004; Kelleci, 2005; Fadiloglı et al., 2006; Arslan et al., 2009). As for hopelessness, it increases stress and negative expectations about future. Patients with cancer experience the feeling of hopelessness deeply in the adjustment process. Hopelessness is caused by perceiving cancer as a negative and deadly disease (Fadıloglı et al., 2006). Hopelessness is

\footnotetext{
${ }^{1}$ Sr. Asst. Professor Department of Psychology, University of Kashmir, Hazratbal Srinagar, India *Responding Author

Received: June 24, 2017; Revision Received: October 29, 2017; Accepted: November 23, 2017

(C) 2017 Rizvi T; licensee IJIP. This is an Open Access Research distributed under the terms of the Creative Commons Attribution License (www.creativecommons.org/licenses/by/2.0), which permits unrestricted use, distribution, and reproduction in any Medium, provided the original work is properly cited.
} 


\section{A Study of Relationship between Hopelessness and Coping Strategies in Cancer Patients}

also one of the most frequent and important conditions described in medically ill patients (Dunn, 2005). The feeling that hopes have been destroyed or that a dilemma cannot be resolved makes hopelessness common in cancer patients. Hopelessness can threaten a patient's physical and psychological well-being and can affect the process of recovery and rehabilitation. Likewise, hopelessness has been found to be present among medically ill patients who meet the criteria for demoralization (i.e., the feeling of having failed to meet one's own expectations or those of other people; feeling unable to cope with a current urgent problem; feelings of helplessness, hopelessness, and/or giving up), according to the Diagnostic Criteria for Psychosomatic Research (DCPR),rather than major depression, according to the DSM-IV.

In oncology, a number of studies have focused on hopelessness as a maladaptive coping style. Hopelessness has been associated with poor adjustment to illness; this includes depression (Classen, Koopmen, Angell, 1996, Ferrero, Barreto, \&Toledo1994), low satisfaction with support received from interpersonal ties and poor quality of life Hopelessness also contributed uniquely to the prediction of suicidal ideation, controlling for level of depression, among cancer patients in an advanced phase of illness (Chochinov., Wilson, \& M. Enns 1998). Furthermore, hopelessness and depression mediated the pathways between illnessrelated factors and desire for hastened death both in hospitalized (Jones, Huggins, \& Rydall, 2003), and terminally-ill cancer patients (Breitbart, Rosenfeld \&Pessin, 2000 Mystakidou, Parpa, \&Tsilika,2007). Research also seems to suggest the possibility of a connection between hopelessness and cancer prognosis. In a 10-year follow-up investigation of 450 breast cancer patients, hopelessness, rather than depression, was shown to predict both recurrence of illness and reduced survival time (Watson, Homewood \&Haviland, 2005). Hopelessness has been shown to be a strong predictor of both incidence of and death from cancer, independent of depression and traditional biological risk factors in generalpopulation studies. Cancer being a potential life-threatening illness engenders considerable psychological distress, requiring persistent coping for the treatment procedures.The role that coping may lay in mediating the psychological impact of cancer has been of considerable clinical and research interest. Coping strategies have been found to be directly related to health status. The emphasis on anxiety and depression as psychiatric symptoms reveals only part of the story about how people cope with disease. Another quite different aspect concerns psychological well-being and the coping processes that support it (Folkman \& Greer, 2000). Therefore coping could be conceptualized as a process somewhat changeable over time and dependent on the type of situation (Lazarus \& Folkman, 1984). Although coping strategies are not inherently adaptive or maladaptive, previous research has consistently found disengagement strategies (i.e., behavioural and cognitive avoidance) to be associated with greater emotional distress, whereas active coping strategies (i.e., acceptance and planning) contribute to greater psychosocial well-being and more positive affect (Carver et. al 1993). This study was conducted with objective to assess the hopelessness and coping strategies in cancer patients and to find out the relationship between these variables. Further the differences in hopelessness and coping strategies were also assessed in disfigured and nondisfigured cancer patients. 


\section{METHODOLOGY}

\section{Sample:}

The target population of this study was 200 cancer patients who were either receiving treatment or were at follow-up at Sheri Kashmir Institute of Medical Studies. The cancer sites studied included breast cancer, stomach cancer, and colorectal cancer. On the basis of treatment impact on patient's ability and function, sample was further divided into two subgroups, those who had suffered disfigurement on account of treatment procedures involved and those who had not suffered any disfigurement.

\section{Instruments:}

1. Becks Hopelessness Scale (Beck, 1974). The measure comprises of 20 self-report items (11 negatively phrased and 9 positively phrased). The items are scored either 1 or 0 . Adequate reliability has been reported for this scale across clinical and nonclinical population with alpha value .80 .

2. Ways of Coping Questionnaire (Folkman \& Lazarus, 1988). The ways of coping questionnaire is a self-report instrument designed to identify the thoughts and actions an individual uses to cope with a specific stressful encounter. It has 66 items divided into 8 sub-scales and responses are scored on a 4-point likert scale.

\section{Procedure:}

Before the study was carried out, the necessary permissions were obtained from the hospital where the study was conducted. The forms were administered by the researcher through face to face interviews with a view to making the participants feel more comfortable, and the informed consents were obtained before administration.

\section{RESULTS}

Table 1: Showing number and percentage of cancer patients falling under three levels of hopelessness.

\begin{tabular}{llc}
\hline Levels of Hopelessness & $\boldsymbol{F}$ & \%age \\
\hline Low & 60 & 30 \\
Moderate & 99 & 49.5 \\
High & 41 & 20.5 \\
\hline
\end{tabular}

Above table shows that 60 out of 200 cancer patients have low levels of hopelessness and 41 out of 200 i.e., 20.5\% of cancer patients are high on hopelessness. The rest i.e., $49.5 \%$ of cancer patients have moderate hopelessness.

Table 2: Showing number and percentage of disfigured cancer patients falling under three levels of hopelessness.

\begin{tabular}{llc}
\hline Levels of Hopelessness & $\boldsymbol{F}$ & \%age \\
\hline Low & 21 & 22.8 \\
Moderate & 48 & 52.1 \\
High & 23 & 25 \\
\hline
\end{tabular}


The table shows that 21 out of 92 disfigured cancer patients have low levels of hopelessness and 23 out of 92 i.e., 25\% of disfigured cancer patients are high on hopelessness. The rest i.e., $52.1 \%$ of disfigured cancer patients have moderate hopelessness.

Table 3: Showing number and percentage of non-disfigured cancer patients falling under three levels of hopelessness

\begin{tabular}{lll}
\hline Levels of Hopelessness & $\boldsymbol{F}$ & \%age \\
\hline Low & 39 & 36.1 \\
Moderate & 51 & 47.2 \\
High & 18 & 16.6 \\
\hline
\end{tabular}

Table 3 reveals that 39 out of 108 non-disfigured cancer patients have low levels of hopelessness and 18 out of 108 i.e., 16.6\% of non-disfigured cancer patients are high on hopelessness. The rest i.e., $47.2 \%$ of non-disfigured cancer patients have moderate hopelessness.

Table 4: Showing mean scores of different coping strategies used by cancer patients

\begin{tabular}{lll}
\hline Coping Strategies & $\boldsymbol{N}$ & Mean \\
\hline Confrontive coping & 200 & 1.066 \\
Distancing & 200 & 1.418 \\
Self-Controlling & 200 & 1.599 \\
Seeking Social Support & 200 & 1.732 \\
Accepting Responsibility & 200 & 1.616 \\
Escape-Avoidance & 200 & 1.151 \\
Planful Problem Solving & 200 & 1.338 \\
Positive Reappraisal & 200 & 1.337 \\
Total & 200 & 11.27 \\
\hline
\end{tabular}

As presented in the table 4 the behaviors which comprise the scale, Seeking Social Support $(M=1.732)$ were used most often, those included in the Confrontive Scale $(M=1.066)$ were used the least among overall sample of cancer patients.

Table 5: Showing mean scores of different coping strategies used by disfigured cancer patients

\begin{tabular}{lll}
\hline Coping Strategies & $\boldsymbol{N}$ & Mean \\
\hline Confrontive coping & 92 & 1.055 \\
Distancing & 92 & 1.348 \\
Self-Controlling & 92 & 1.519 \\
Seeking Social Support & 92 & 1.695 \\
Accepting Responsibility & 92 & 1.665 \\
Escape-Avoidance & 92 & 1.134 \\
Planful Problem Solving & 92 & 1.292 \\
Positive Reappraisal & 92 & 1.231 \\
Total & 92 & 10.932 \\
\hline
\end{tabular}


As presented in the table 5 the behaviors which comprise the scale, Seeking Social Support $(M=1.695)$ were used most often, those included in the Confrontive Scale $(M=1.055)$ were used the least among disfigured cancer patients.

Table 6: Showing mean scores of different coping strategies used by non-disfigured cancer patients

\begin{tabular}{lll}
\hline Coping Strategies & $\boldsymbol{N}$ & Mean \\
\hline Confrontive coping & 108 & 1.075 \\
Distancing & 108 & 1.477 \\
Self-Controlling & 108 & 1.667 \\
Seeking Social Support & 108 & 1.764 \\
Accepting Responsibility & 108 & 1.574 \\
Escape-Avoidance & 108 & 1.165 \\
Planful Problem Solving & 108 & 1.378 \\
Positive Reappraisal & 108 & 1.427 \\
Total & 108 & 11.57 \\
\hline
\end{tabular}

As presented in the table 6 the behaviors which comprise the scale, Seeking Social Support $(M=1.764)$ were used most often, those included in the Confrontive Scale $(M=1.075)$ were used the least among non-disfigured cancer patients.

Table 7: Showing correlation between hopelessness and different coping strategies among cancer patients

\begin{tabular}{|c|c|c|}
\hline \multirow{2}{*}{$\begin{array}{l}\text { Coping Subscales } \\
\text { Confrontive Coping }\end{array}$} & & Hopelessness \\
\hline & $\begin{array}{l}R \\
\text { N } 200\end{array}$ & $-0.064^{\mathrm{NS}}$ \\
\hline Distancing & $\begin{array}{l}R \\
\text { N } 200\end{array}$ & $-0.492 * *$ \\
\hline Self-Controlling & $\begin{array}{l}R \\
\text { N } 200\end{array}$ & $-0.410 * *$ \\
\hline Seeking Social Support & $\begin{array}{l}R \\
\text { N } 200\end{array}$ & $-0.24 * *$ \\
\hline Accepting Responsibility & $\begin{array}{l}R \\
\text { N } 200\end{array}$ & $-0.174^{*}$ \\
\hline Escape Avoidance & $\begin{array}{l}R \\
\text { N } 200\end{array}$ & $-0.03^{\mathrm{NS}}$ \\
\hline Planful Problem Solving & $\begin{array}{l}R \\
\text { N } 200\end{array}$ & $-0.39 * *$ \\
\hline Positive Reappraisal & $\begin{array}{l}R \\
\text { N } 200\end{array}$ & $-0.439 * *$ \\
\hline Total & $\begin{array}{l}R \\
\text { N } 200\end{array}$ & $-0.436 * *$ \\
\hline
\end{tabular}

$* * \mathrm{p} \leq 0.01, * * \mathrm{p} \leq 0.05, \mathrm{NS}$, Insignificant

Result from the table 7 reveal that there is no significant correlation between hopelessness and two of the coping strategies namely, Confrontive coping and escape avoidance in overall 
sample of cancer patients. However, significant negative correlation exists between hopelessness and certain other coping streategies namely, use of distancing ( $\mathrm{r}=-0.492)$, selfcontrolling ( $\mathrm{r}=-0.410)$, seeking social support $(\mathrm{r}=-0.24)$, accepting responsibility $(\mathrm{r}=-0.174)$, Planful problem solving $(\mathrm{r}=-0.39)$ and positive reappraisal $(\mathrm{r}=-0.439)$. The correlation values between hopelessness and all the mentioned strategies are significant at 0.01 level except the correlation value between hopelessness and accepting responsibility, which is significant at 0.05 level. Also, significant negative correlation exists between hopelessness and overall score of coping $(r=-0.436)$, the correlation value is significant at 0.01 level.

Table 8: Showing correlation between hopelessness and different coping strategies among disfigured cancer patients

\begin{tabular}{|c|c|c|}
\hline \multirow{2}{*}{$\begin{array}{l}\text { Coping Subscales } \\
\text { Confrontive Coping }\end{array}$} & & Hopelessness \\
\hline & $\begin{array}{l}R \\
\text { N } 92\end{array}$ & $-0.124^{\mathrm{NS}}$ \\
\hline Distancing & $\begin{array}{l}R \\
\text { N } 92\end{array}$ & $-0.463 * *$ \\
\hline Self-Controlling & $\begin{array}{l}R \\
\text { N } 92\end{array}$ & $-0.347 * *$ \\
\hline Seeking Social Support & $\begin{array}{l}R \\
\text { N } 92\end{array}$ & $-0.230 *$ \\
\hline Accepting Responsibility & $\begin{array}{l}R \\
\text { N } 92\end{array}$ & $-0.262 *$ \\
\hline Escape Avoidance & $\begin{array}{l}R \\
\text { N } 92\end{array}$ & $-0.121^{\mathrm{NS}}$ \\
\hline Planful Problem Solving & $\begin{array}{l}R \\
\text { N } 92\end{array}$ & $-0.359 * *$ \\
\hline Positive Reappraisal & $\begin{array}{l}R \\
\text { N } 92\end{array}$ & $-0.381 * *$ \\
\hline Total & $\begin{array}{l}R \\
\text { N } 92\end{array}$ & $-0.441 * *$ \\
\hline
\end{tabular}

$* * \mathbf{p} \leq 0.01, * * \mathbf{p} \leq 0.05, \mathrm{NS}$, Insignificant

Result from the table 8 reveal that there is no significant correlation between hopelessness and two of the coping strategies namely, Confrontive coping and Escape avoidance coping strategies in disfigured cancer patients. However, significant negative correlation exists between hopelessness and certain other coping strategies namely distancing ( $\mathrm{r}=-0.347)$, seeking social support $(\mathrm{r}=-0.230)$, accepting responsibility $(\mathrm{r}=-0.262)$, Planful problem solving $(r=-0.359)$ and positive reappraisal $(r=-0.381)$. The correlation values between hopelessness and all the mentioned strategies are significant at 0.01 level except the correlation value between hopelessness and coping strategy seeking social support and accepting responsibility, , which are significant at 0.05 level.Also, significant negative correlation exists between hopelessness and overall score of coping ( $r=-0.441)$, the correlation value is significant at 0.01 level. 
Table 9: Showing correlation between hopelessness and different coping strategies among non-disfigured

\begin{tabular}{|c|c|c|}
\hline \multirow{2}{*}{$\begin{array}{l}\text { Coping Subscales } \\
\text { Confrontive Coping }\end{array}$} & & Hopelessness \\
\hline & $\begin{array}{l}R \\
\text { N108 }\end{array}$ & $-0.01^{\text {NS }}$ \\
\hline Distancing & $\begin{array}{l}R \\
\text { N108 }\end{array}$ & $-0.50 * *$ \\
\hline Self-Controlling & $\begin{array}{l}R \\
\mathrm{~N} 108\end{array}$ & $-0.42 * *$ \\
\hline Seeking Social Support & $\begin{array}{l}R \\
\mathrm{~N} 108\end{array}$ & $-0.23 *$ \\
\hline Accepting Responsibility & $\begin{array}{l}R \\
\text { N } 108\end{array}$ & $-0.13^{\mathrm{NS}}$ \\
\hline Escape Avoidance & $\begin{array}{l}R \\
\mathrm{~N} 108\end{array}$ & $-0.057^{\mathrm{NS}}$ \\
\hline Planful Problem Solving & $\begin{array}{l}R \\
\mathrm{~N} 108\end{array}$ & $-0.402 * *$ \\
\hline Positive Reappraisal & $\begin{array}{l}R \\
\mathrm{~N} 108\end{array}$ & $-0.465 * *$ \\
\hline Total & $\begin{array}{l}R \\
\text { N } 108\end{array}$ & $-0.414^{* *}$ \\
\hline
\end{tabular}

$* * \mathrm{p} \leq 0.01$ level, $* * \mathrm{p} \leq 0.05, \mathrm{NS}$, Insignificant

Table 9 shows that there is no significant correlation between hopelessness and three of the coping strategies namely, Confrontive coping, Accepting responsibility and Escape avoidance coping strategies in non-disfigured cancer patients. However, significant negative correlation exists between hopelessness and certain other coping strategies namely use of distancing ( $\mathrm{r}=-0.50)$, self-controlling ( $\mathrm{r}=-0.42)$, seeking social support $(\mathrm{r}=-0.23)$, Planful problem solving $(\mathrm{r}=-0.402)$ and positive reappraisal $(\mathrm{r}=-0.465)$. The correlation values between hopelessness and all the mentioned strategies are significant at 0.01 level except the correlation value between hopelessness and seeking social support which is significant at 0.05 level. Also, significant negative correlation exists between hopelessness and overall score of coping $(r=-0.414)$, the correlation value is significant at 0.01 level.

Table 10: Showing comparison of mean scores of hopelessness among cancer patients whose treatment has caused disfigurement and whose treatment has not caused disfigurement

\begin{tabular}{llllll}
\hline Scale & $\begin{array}{l}\text { Treatment } \\
\text { Modality }\end{array}$ & Number & Mean & $\begin{array}{l}\text { Std. } \\
\text { Deviation }\end{array}$ & t-value \\
\hline Hopelessness & $\begin{array}{c}\text { Disfigured } \\
\text { Non- } \\
\text { disfigured }\end{array}$ & 92 & 12.55 & 4.06 & $2.43^{*}$ \\
\hline
\end{tabular}

*p $\leq 0.05$

Table 11 reveals, that there exists a significant difference between disfigured and nondisfigured cancer patients in terms of their hopelessness score $(t=2.43)$, the $t$-value is significant at 0.05 level. The disfigure group tends to score high on hopelessness.

(C) The International Journal of Indian Psychology, ISSN 2348-5396 (e)| ISSN: 2349-3429 (p) | 41 


\section{DISCUSSION}

Cancer patients were found to be on moderate level of hopelessness in both treatment groups but in disfigured cancer group the percentage of hopeless patients was found to be more than among the non-disfigured group. Regarding the use of coping strategies, seeking social support was used most frequently by patients and Confrontive coping was used least. Assessing the relationship between hopelessness and different coping strategies, there was significant negative correlation between hopelessness and use of coping strategies viz. distancing, self-controlling, accepting responsibility, planful problem solving and positive appraisal. The results are in line with the previous results on patients with cancer (Danheur, et, al, 2009).On comparing the disfigured and non-disfigured group on their hopelessness, the level was more in disfigured group. Comparing the same groups on using different coping strategies, it was found that the use of self-controlling and positive reappraisal were less in disfigured group.

\section{LIMITATIONS AND IMPLICATIONS}

The findings of this study should be interpreted with care. First of all the sample in this study is a convenience sample and not the probability one, so care should be taken to generalize the results because of the representativeness issues. Second, it is difficult to infer the causality in co relational studies, so in future longitudinal studies should be conducted with large sample size so that relationship between hopelessness and coping becomes clearer.

The findings of this study can have implications for clinicians and oncology nurses because they are in a key position to incorporate psychosocial care in their daily practice. The finding of this study that there is a negative correlation between coping strategies and hopelessness has also implications for cognitive-behavioral interventions providing further support to coping as a target of intervention.

\section{Acknowledgments}

The author appreciates all those who participated in the study and helped to facilitate the research process.

Conflict of Interests: The author declared no conflict of interests.

\section{REFERENCES}

Arslan, S., Celebioglu, A., \&Tezel, A (2009).Depression and hopelessness in Turkish patients with cancer undergoing chemotherapy.Jpn J NursSci, 6, 105-10.

Beck, A.T, Weissman, A,\& Lester, D. (1974). The measurement of pessimism: the hopelessness scale. J Consult ClinPsychol, 42, 861-865.

Breitbart, B. Rosenfeld,\& H. Pessin.(2000). Depression, hopelessness, and desire for hastened death in terminally ill patients with cancer.JAMA, 284, 2907-291.

Carver C. S, Pozo C, Harris S.D., Noriega V, Scheier M.F., Robinson D.S., Ketcham A.S, Moffat F.L Jr., \&Clark K.C. (1993). How coping mediates the effect of optimism on 


\section{A Study of Relationship between Hopelessness and Coping Strategies in Cancer Patients}

distress: A study of women with early stage breast cancer. J PersSocPsychol, 65, 375-390.

Chochinov.,H.M., Wilson,K.G. \& Enns,M. (1998).Depression, hopelessness, and suicidal ideation in the terminally ill. Psychosomatics, 39, 366-370.

Classen, C. Koopman, \&K. Angell (1996).Coping styles associated with psychological adjustment to advanced breast cancer. Health Psychol, 15,434-43

Danhauer, S. C., Crawford, S. L., Farmer, D. F et al. (2009). A longitudinal investigation of coping strategies and quality of life among younger women with breast cancer. JBehav Med, 32, 371-379.

Dunn,S.L. (2005). Hopelessness as a response to physical illness. JNurs Scholarship, 37, $148-154$.

Fadıloğlı, Ç, Cantilav Ş, \&Yıldırım KY, et al (2006).The relationship between level of hopelessness and coping behaviours in women with breast cancer.Ege University School of Nur J, 22, 147-60.

Ferrero, J., Barreto, M.P. \&Toledo,M. (1994). Mental adjustment to cancer and quality of life in breast cancer patients: an exploratory study. Psychooncology, 3,223-232

Folkman, S\& Greer, S. (2000).Promoting psychological wellbeing in the face of serious illness: When theory, research and practice inform each other. Psychooncology, 9, 11-19.

Jones, J.M.. Huggins, M.A\&. Rydall A.C. (2003). Symptomatic distress, hopelessness, and the desire for hastened death in hospitalized cancer patients. JPsychosom Res, 55, 411-418.

Kelleci, M (2005). Kanserhastalarınınumudunungeliştirilmesineyönelikhemşirelikgirişimleri. Anadolu Psikiyatr iDergisi, 6, 41-47.

Lazarus J. T, \& Folkman, S (1984) Coping and adaption; in: Gentry WD (ed): Handbook of Behavioral Medicine. New York, Guilford, p. 10.

Mystakidou, E. Parpa, K \&Tsilika,E. (2007). Depression, hopelessness, and sleep in cancer patients' desire for death.Int J Psychiatry Med, 37, 201-211.

Öz, F (2004). Problem areas and characteristics of cancer patients applied to department of mental health in hacettepe university oncology hospital. $J$ Turk Hematology Oncol, 1, 33-9.

Watson, J. Homewood, W \& Haviland,J. (2005). Influence of psychological response on breast cancer survival: 10-year follow-up of a population-based cohort. Eur J Cancer, 41, 1710-1714.

How to cite this article: Rizvi T (2017). A Study of Relationship between Hopelessness and Coping Strategies in Cancer Patients. International Journal of Indian Psychology, Vol. 5, (1), DIP:18.01.044/20170501, DOI:10.25215/0501.044 